\title{
USP LANÇA GUIA PRÁTICO SOBRE ENSINO E EDUCAÇÃO COM IGUALDADE DE GÊNERO
}

Duas entidades da Universidade de São Paulo (USP) lançaram recentemente um Guia sobre igualdade de gênero na escola, que causou grande repercussão nos meios de comunicação. O trabalho, Ensino e Educação com Igualdade de Gênero na Infância e Adolescência: Guia Prático para Educadores e Educadoras, recebeu reconhecimento dos mais importantes meios de comunicação do país.

O Guia foi elaborado no contexto do convênio celebrado entre o Ministério da Educação e do Desporto (MEC) e a USP, pela sua Coordenadoria Executiva de Cooperação Universitária e Atividades Especiais (CECAE). O Núcleo de Estudos da Mulher e Relações Sociais de Gênero (NEMGE) foi convidado a participar do Programa Nacional de Atenção Integral à Criança e ao Adolescente (PRONAICA) para estudar a questão de gênero nas propostas, conteúdos programáticos e ensino nas salas de aula dos Centros de Atenção Integral à Criança e ao Adolescente (CAICs) do Estado de São Paulo, e a oferecer sugestões aos/às professores/as no que diz respeito a este tema. Deste trabalho resultou, em junho de 1996, a publicação do Guia, que foi distribuído aos CAICs, às Oficinas Pedagógicas e demais órgãos pedagógicos da Secretaria de Educação do Estado de São Paulo.

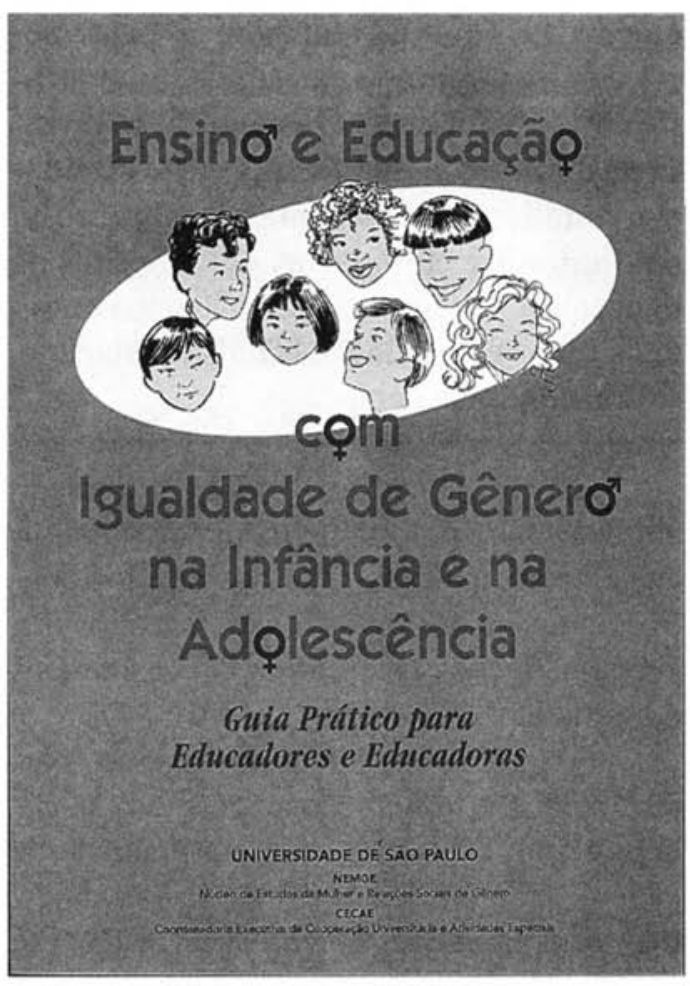

Reprodução da capa do Guia.

\section{AS AUTORAS}

Profa. Dra. Rosa Ester Rossini

Dra. Rochelle G. Saidel

Dra. Sônia A. Calió

Pesquisadora Isamara L. Jesus

1. Pesquisadoras do Núcleo de Estudos da Mulher e Relações Sociais de Gênero - NEMGE/USP e autoras do Guia. 
A elaboração deste Guia coincidiu com a recente assinatura do Protocolo de Cooperação celebrado entre os Ministérios da Justiça e o da Educação e do Desporto, com vista à promoção da igualdade de direitos entre homens e mulheres. Representa, talvez, a primeira concretização efetiva do espírito do Protocolo.

O NEMGE elaborou este Guia após pesquisa de campo - visita aos CAICs, entrevista com diretores/as e professores/as e estudantes - e pesquisa bibliográfica. Este trabalho serve como instrumento de orientação, auto-avaliação e atividades didáticas aos/às professores/as, a fim de diminuir e eliminar os preconceitos de gênero e o sexismo veiculados pelos materiais didáticos, pelos manuais escolares e, sobretudo, pela sociedade.

Cabe destacar que o Guia é ilustrado com cartuns, importante forma de comunicação, principalmente, se nos dermos conta de que a maioria dos livros didáticos trazem ilustrações estereotipadas de homens e mulheres.

O trabalho está dividido em cinco partes, incluindo introdução ao conceito de gênero e auto-avaliação sobre a igualdade de gênero. Contém ainda estratégias e sugestões para promover a igualdade de gênero na sala de aula, nos esportes e educação física, nas atividades lúdicas, no trabalho, na família, na comunidade, enfatizando a importância da auto-estima da criança e o ensino de sexualidade e saúde. Apresentam sugestões e possíveis soluções para evitar o sexismo na linguagem e, ainda, bibliografia temática, lista de vídeos, fontes de informações e outros recursos.

Além da experiência de trabalho junto às escolas, vale salientar que se realizou um amplo levantamento bibliográfico sobre o tema e, em especial, destacaram-se as publicações elaboradas por Zuleika Alambert, Isabel Romão, André Michel, Fábio Otuzi Brotto, Kathryn Wheeler, pela ONU e UNESCO.

A seguir, alguns trechos do trabalho para melhor apresentá-lo.

\section{UMA INTRODUÇÃO AO CONCEITO DE GÊNERO}

\section{O que é Gênero?}

Gênero é um conceito que identifica o tipo de relação social que se estabelece entre homens e mulheres.

As relações de gênero são socialmente construídas e, como tal, específicas às formações sociais mutáveis diante de alterações econômicas e culturais.

Por outro lado, o termo sexo é diferente de gênero e diz respeito às diferenças biológicas entre homens e mulheres.

O que é igualdade e eqüidade de gênero?

De acordo com o Novo Dicionário Aurélio da Língua Portuguesa, igualdade é a relação entre os indivíduos em virtude da qual todos eles são portadores dos mesmos direitos fundamentais que provêm da humanidade e definem a dignidade da pessoa humana. Quando falamos em igualdade de gênero, estamos aplicando essa definição às relações sociais entre as mulheres e os homens. Nesse sentido, a igualdade de direitos, de oportunidades e de acesso aos recursos, a distribuição eqüitativa das responsabilidades relativas à família são indispensáveis ao bem-estar de mulheres e de homens. 
Eqüidade de gênero refere-se à igualdade de oportunidades, ao respeito pelas diferenças existentes entre homens e mulheres e às transformações das relações de poder que se dão na sociedade em nível econômico, social, político e cultural, assim como à mudança das relações de dominação na família, na comunidade e na sociedade em geral.

O que é preconceito de gênero?

Chamado também de sexismo, o preconceito de gênero é uma atitude social que diminui ou exclui as pessoas, em geral as mulheres, de acordo com o seu sexo. Relacionado ao pensamento e aos hábitos individuais e sociais, envolve atitudes que afetam o comportamento e, freqüentemente, nem são percebidas.

A discriminação de sexo é um pouco diferente do preconceito de gênero, porque se refere a tipos de comportamento e práticas individuais e institucionais que, de modo claro, são discriminatórias com base no sexo e, em conseqüência, são contra a lei. Por exemplo: segundo a Constitução Brasileira, "homens e mulheres são iguais em direitos e obrigações, nos termos desta Constituição" (Art. 5, § $\left.1^{\circ}\right)$. Qualquer instituição e qualquer cidadão/ã que não cumpra este artigo está cometendo um ato ilegal. Ambos - discriminação de sexo e preconceito de gênero podem ser dissimulados, já que muitos aspectos do preconceito de gênero são sutis e inconscientes, porque estão embutidos nos comportamentos.

O foco deste Guia é o preconceito de gênero, porque esta é uma atitude que pode ser mudada por professores/as na sala de aula.

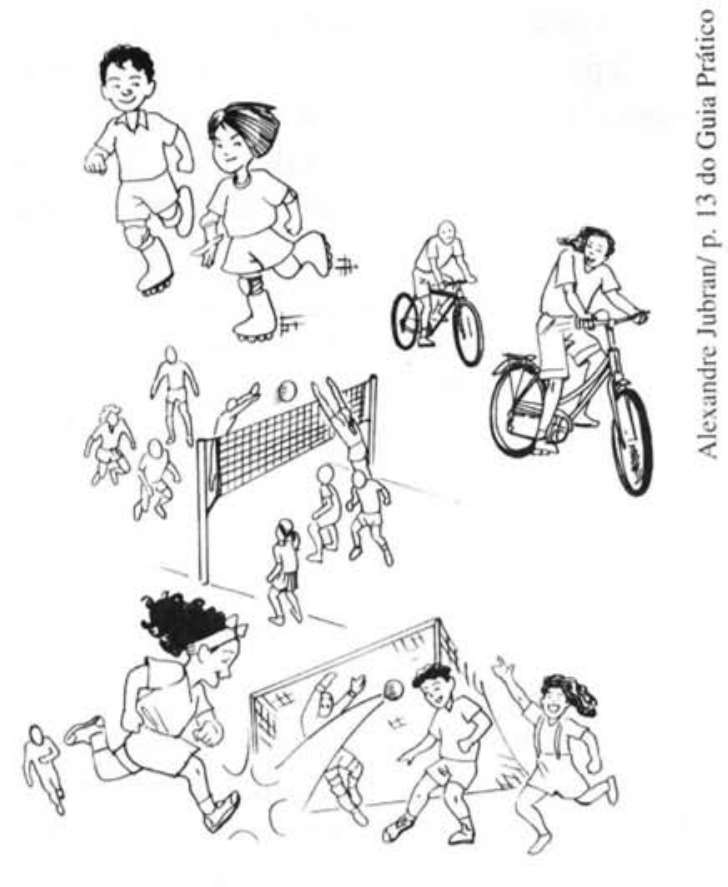

O que é estereótipo de gênero?

O estereótipo de gênero está ligado ao preconceito de gênero. É uma opinião predeterminada, que afeta as relações interpessoais.

O estereótipo aparece como uma forma rígida, anônima, reproduz imagens e comportamentos e separa os indivíduos em categorias. Um exemplo de estereótipo de gênero: as meninas são choronas e os meninos não podem chorar.

O preconceito de gênero na sala de aula, ...

Embora tenhamos consciência de que a questão de gênero permeia toda a sociedade, nas mais diferentes formas e disfarces, a escola será nossa preocupação central.

É importante ressaltar que as sugestões aqui apresentadas terão resultado mais efetivo na medida em que forem assumidas 
pela Unidade de Ensino como um todo e não apenas por agentes isolados. Cada professor/a, portanto, poderá adaptá-las às condições de suas próprias salas de aula e oferecer, assim, um ambiente mais justo para todos/as os meninos e as meninas.

Este Guia pretende ajudar as/os professoras/es nesta tarefa difícil, mas fundamentalmente necessária - a luta pela construção de uma sociedade com igualdade e eqüidade de gênero.

\section{.... nos livros e materiais didáticos}

As imagens de homens e mulheres apresentadas nos manuais escolares não refletem, em geral, a realidade em que vivem hoje as crianças e não oferecem às meninas a mesma igualdade de oportunidades dada aos meninos. Na apresentação da "vida" e da "família" (relações entre casal e filhos/as, marido e mulher, pai e mãe), deve ser considerado que a divisão dos papéis e das tarefas da mulher e do homem na vida moderna também está em evolução.

Como primeiro passo para enfrentar o preconceito de gênero dos livros e dos manuais escolares, os/as professores/as deyem reconhecer que estes materiais, em geral, não apresentam imagens justas em relação ao gênero e precisam introduzir outras atividades didáticas, algumas das quais apresentaremos aqui.

\section{A importância do papel da escola e do/a professor/a}

As crianças aprendem o sexismo na escola ao se defrontar com a hierarquia do sistema escolar, onde os papéis feminino e masculino estão determinados. Tal sistema define que, no futuro, os homens serão dirigentes no mundo do trabalho e as mulheres ocuparão o segundo lugar nos processos de decisão. $\mathrm{O}$ que limita as ambições das meninas.

É necessário, desde o início, ter uma postura crítica em relação aos materiais pedagógicos utilizados na escola. Estes são, em grande parte, veículos que reproduzem mensagens sexistas e preconceituosas.

O objetivo deste Guia, portanto, é proporcionar aos/às educadores/as instrumentos que ajudem a introduzir esta "postura crítica" ao cotidiano de seu trabalho, permitindo-lhes enfrentar e erradicar o sexismo dentro e fora da escola.

\section{PARE E PENSE - AUTO-AVALIAÇÃO SOBRE A IGUALDADE DE GÊNERO}

As perguntas, abaixo apresentadas, são exemplos de um instrumento de auto-avaliação contido no Guia e justifica-se no sentido de estimular a criação de um ambiente com igualdade e eqüidade de gênero.

Realizada esta auto-avaliação, sem a necessidade de contar pontos, verifique a possibilidade de mudar algumas posturas. Volte freqüentemente a ela e constate o quanto está ajudando nas atividades de ensino com igualdade de gênero.

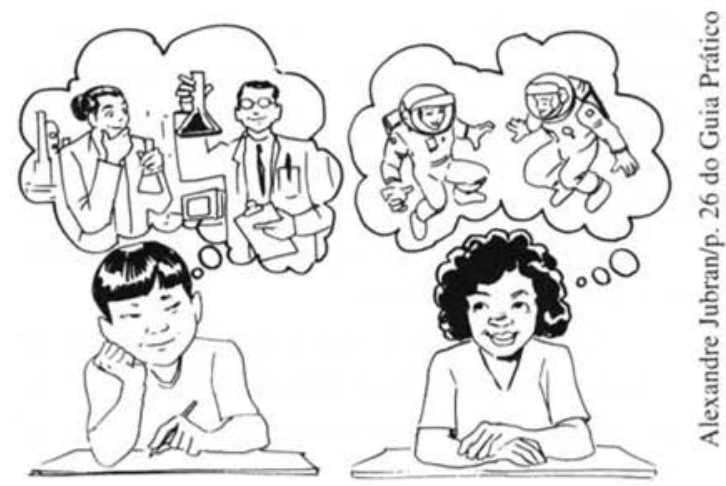




\section{AUTO-AVALIAÇÃO}

\section{LISTA DAS PERGUNTAS}

(respostas possiveis:sim/às vezes/não)

* Encorajo as meninas a não esconder suas capacidades?

* Tenho a expectativa de que todos/as os/as alunos/as explorem as várias opções de engajamento profissional? Encorajo todos/as os/as alunos/as, incluindo meninas grávidas, a não abandonar os estudos?

* Acho que tanto as meninas como os meninos podem desenvolver habilidades de liderança?

* Oriento meninas e meninos a desenvolver habilidades tanto para escutar como para falar?
* Incentivo meninas e meninos a praticar esportes, mas respeito os/as que não gostam de práticas esportivas?

* Estou atento/a ao fato que muitas/os meninas/os têm uma imagem negativa do próprio corpo?

* Compreendo que o preconceito de gênero é um problema da sociedade, e não do indivíduo?

* Tento conscientizar os/as estudantes sobre como acontece o preconceito de gênero ?

\section{COMO EVITAR O SEXISMO NA LINGUAGEM}

$\mathrm{O}$ seguinte quadro mostra algumas sugestões e possíveis soluções que constam do Guia.

\begin{tabular}{|c|c|c|c|}
\hline CASOS & USOS CORRENTES & POSSÍVEIS SOLUÇÕES & COMENTÁRIOS \\
\hline $\begin{array}{l}\text { Emprego do masculino } \\
\text { com valor genérico }\end{array}$ & "O homem", "os homens" & $\begin{array}{l}\text { Os homens e as mulheres } \\
\text { Os seres humanos } \\
\text { A humanidade } \\
\text { As pessoas }\end{array}$ & $\begin{array}{l}\text { Evitar o uso genérico de } \\
\text { o homem, os homens. }\end{array}$ \\
\hline Os Direitos Humanos & $\begin{array}{l}\text { "Os Direitos do Homem" } \\
\text { "Os Direitos dos Homens" }\end{array}$ & $\begin{array}{l}\text { Os Direitos Humanos } \\
\text { Os Direitos da Humanidade }\end{array}$ & $\begin{array}{l}\text { São direitos de todos/as } \\
\text { (mulheres e homens). }\end{array}$ \\
\hline $\begin{array}{l}\text { Uso permanente } \\
\text { de estereótipos }\end{array}$ & $\begin{array}{l}\text { Referir-se ao/a professor/a } \\
\text { como "o tio", "a tia" } \\
\text { "Menino brinca com bola." } \\
\text { "Menina brinca com boneca." }\end{array}$ & $\begin{array}{l}\text { A professora Helena } \\
\text { O professor José } \\
\text { Não há brinquedo ou } \\
\text { brincadeira específica para } \\
\text { cada sexo. Meninos e meninas } \\
\text { brincam juntos com o mesmo } \\
\text { tipo de brinquedo. }\end{array}$ & $\begin{array}{l}\text { Evitar identificar as pessoas } \\
\text { pela profissão que exercem. } \\
\text { como se fossem anônimas. } \\
\text { Evitar o uso das expressões } \\
\text { "Isto é brinquedo de menino"; } \\
\text { "Esta brincadeira é para meninas". }\end{array}$ \\
\hline $\begin{array}{l}\text { Os julgamentos } \\
\text { subjetivos }\end{array}$ & $\begin{array}{l}\text { "Menino não chora." } \\
\text { "Forte como um menino." } \\
\text { "Frágil como uma menina." }\end{array}$ & $\begin{array}{l}\text { Criança chora. } \\
\text { O menino e a menina são } \\
\text { fortes e corajosos. }\end{array}$ & $\begin{array}{l}\text { Mostrar meninos e meninas como } \\
\text { igualmente capazes em termos de } \\
\text { maturidade, dedicação, autocontrole, } \\
\text { doçura, gentileza, imaturidade, } \\
\text { egoísmo, sensibilidade em relação } \\
\text { aos outros, motivaçâo, rudeza, } \\
\text { subjetividade etc. }\end{array}$ \\
\hline $\begin{array}{l}\text { Na esfera profissional. } \\
\text { o tratamento entre } \\
\text { gêneros é diferente }\end{array}$ & $\begin{array}{l}\text { Nas ilustrações didáticas e nos } \\
\text { livros escolares, a mulher aparece, } \\
\text { em geral, exercendo } \\
\text { atividades no lar, o homem, no } \\
\text { escritório, na oficina etc. }\end{array}$ & $\begin{array}{l}\text { Dar visibilidade às mulheres } \\
\text { que trabalham fora de casa. } \\
\text { Destacar a importância do } \\
\text { trabalho no lar - tanto para } \\
\text { as mulheres, como para homens. }\end{array}$ & $\begin{array}{l}\text { Apresentar mulher e homem em } \\
\text { todos os tipos de trabalho e funções } \\
\text { profissionais. Observar que as } \\
\text { mulheres desempenham papéis sociais } \\
\text { e políticos em todos os níveis, com } \\
\text { igual competência, autoridade e } \\
\text { espírito de iniciativa que seus } \\
\text { colegas homens. }\end{array}$ \\
\hline
\end{tabular}




\section{CONSIDERAÇÕES FINAIS}

Para erradicar o sexismo do cotidiano das pessoas, não basta eliminá-lo dos manuais e dos livros escolares. É necessária, também, a mudança de mentalidade, tanto dos/das educadores/as quanto da família, da escola e da sociedade em geral.

É necessário integrar ao cotidiano da prática pedagógica exemplos, referências e atividades que fomentem a reflexão sobre o tema e uma efetiva mudança de mentalidade.

Este Guia é o primeiro esforço do NEMGE/USP para colaborar com os/as educadores/as que têm a incumbência - de

Resumo: O Núcleo de Estudos da Mulher e Relaçōes Sociais de Gênero (NEMGE) produziu o Guia Prático sobre Ensino e Educação com igualdade de gênero, com o objetivo de colaborar para o desenvolvimento de um trabalho pedagógico crítico e sem preconceitos, evitando o sexismo na linguagem e visando garantir, para meninos e meninas, os mesmos direitos e acesso a oportunidades.

Palavras-chave: gênero, igualdade, discriminação, educaçāo, NEMGE, Guia um lado, desafiadora, mas, afinal de contas, grandemente satisfatória - de contribuir para formar o espírito e as atitudes de crianças e adolescentes, tendo em vista um futuro e uma cidadania com igualdade de gênero.

Para contato: Equipe do Guia NEMGE/USP Cidade Universitária - Prédio da Antiga Reitoria, 3\% andar - 05508-900 São Paulo/SP

Fone: 818-4180/4210 Fax. 818-4308

Para adquirir o Guia:

CECAE/USP Cidade Universitária - Prédio Antiga Reitoria, $7^{\circ}$ andar - CEP 05508-900 - São Paulo/SP. Tel: 818-4495/4496 Fax:

211-0922 Falar com Marta Pimenta

Abstract: The Center for Studies of the Women and Social Relationships of GENDER (Núcleo de Estudos da Mulher e Relaçōes Sociais de Gênero - NEMGE) produced the Practical Guide-book about the Teachin and Education with gerder equality. ITs purpose is to contribute for the development of a serious and unprejudiced pedagogical work, aeroiding the sexism in language and trying to ensure, to boys and girls, the same rights and opportunities.

Palavras-chave: gender, equality, discrimination, education, NEMGE, Guide-book 